ARTICLE

DOI: $10.1038 /$ s41467-018-05945-4

\title{
Loss of PRC1 induces higher-order opening of Hox loci independently of transcription during Drosophila embryogenesis
}

\author{
Thierry Cheutin $^{1} \&$ Giacomo Cavalli id ${ }^{1}$
}

Polycomb-group proteins are conserved chromatin factors that maintain the silencing of key developmental genes, notably the Hox gene clusters, outside of their expression domains. Depletion of Polycomb repressive complex 1 (PRC1) proteins typically results in chromatin unfolding, as well as ectopic transcription. To disentangle these two phenomena, here we analyze the temporal function of two PRC1 proteins, Polyhomeotic (Ph) and Polycomb (Pc), on Hox gene clusters during Drosophila embryogenesis. We show that the absence of $\mathrm{Ph}$ or $\mathrm{Pc}$ affects the higher-order chromatin folding of Hox clusters prior to ectopic Hox gene transcription, demonstrating that PRC1 primary function during early embryogenesis is to compact its target chromatin. Moreover, the differential effects of Ph and Pc on Hox cluster folding match the differences in ectopic Hox gene expression observed in these two mutants. Our data suggest that PRC1 maintains gene silencing by folding chromatin domains and impose architectural layer to gene regulation.

\footnotetext{
${ }^{1}$ Institute of Human Genetics, CNRS and the University of Montpellier, Montpellier, France. Correspondence and requests for materials should be addressed to T.C. (email: thierry.cheutin@igh.cnrs.fr) or to G.C. (email: giacomo.cavalli@igh.cnrs.fr)
} 


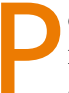
cG proteins are conserved epigenetic components, essential for cell differentiation, which maintain gene silencing during development ${ }^{1-3}$. Genome-wide studies have revealed large $\mathrm{H} 3 \mathrm{~K} 27 \mathrm{me} 3$ chromatin domains bound by $\mathrm{PcG}$ proteins, and Polycomb (Pc) domains fold into distinct nuclear structures ${ }^{4-8}$. Hox gene clusters are the best characterized PcG targets and the loss of PcG proteins affects both Hox gene expression and chromatin compaction in Drosophila and mammalian cells ${ }^{9-11}$. In Drosophila embryos, Hox genes are grouped into two large chromatin clusters of $350-400 \mathrm{~kb}$, covered by histone $\mathrm{H} 3 \mathrm{~K} 27 \mathrm{me} 3^{4,12-14}$. The Antennapedia complex (ANT-C) includes lab, $p b, D f d, S c r$, and Antp, which control the cell identity of anterior segments, whereas the bithorax complex (BX-C) contains $U b x, a b d A$, and $A b d B$ genes, which are responsible for the identity of posterior segments ${ }^{15,16}$.

PcG proteins form two main classes of complexes, PRC2, which is responsible for the deposition of $\mathrm{H} 3 \mathrm{~K} 27 \mathrm{me} 3$ of histone $\mathrm{H} 3^{17}$ and PRC1. PRC1 complexes are further subdivided into canonical PRC1 (cPRC1), which contains the Pc protein that binds to $\mathrm{H} 3 \mathrm{~K} 27 \mathrm{me} 3$ via its chromo domain ${ }^{18}$, and non-cPRC1 complexes, which lack Pc and contain other subunits ${ }^{3}$. In flies, Hox gene expression is regulated by $\mathrm{CPRC1}$, which is composed of Sce, Psc-Suz2, and two proteins that are specific components of this complex: Ph and Pc. The mechanism by which cPRC1 mediates gene silencing is not understood. It has been shown that PRC1 is involved in chromatin compaction in vitro ${ }^{19,20}$ and in vivo ${ }^{10,11,21-25}$, but it is unknown whether PRC1-dependent transcriptional silencing is a consequence of its role on higherorder chromatin folding or whether higher-order chromatin compaction may instead be a consequence of silencing.

Here, in order to distinguish whether higher-order chromatin folding precedes PRC1-dependent transcriptional silencing, we analyze the time-course of 3D chromatin compaction and Hox gene expression in wild-type (WT) or in mutant embryos in which Ph or Pc are deleted. We show that the absence of Ph or Pc affects the higher-order chromatin folding of Hox clusters prior to ectopic Hox gene transcription, demonstrating that PRC1 primary function during early embryogenesis is to compact its target chromatin. During later embryogenesis, we observe further chromatin opening at Hox complexes in both Ph and Pc mutants, which is coupled to strong deregulation of Hox genes at this stage of development. Moreover, the differential effects of $\mathrm{Ph}$ and $\mathrm{Pc}$ on Hox cluster folding matches the differences in ectopic Hox gene expression observed in these two mutants, suggesting that the degree of Hox derepression in PcG mutants depends on the degree of structural constraints imposed by each PcG component.

\section{Results}

Correlation between Hox transcription and chromatin folding. We first performed RNA fluorescence in situ hybridization (FISH) experiments in WT embryos to detect nascent transcripts of eight Drosophila Hox genes, using probes recognizing the first introns of those genes (Fig. 1a). As expected, our results show collinear expression of $l a b, p b, D f d, S c r, A n t p, U b x, a b d A$, and $A b d B$ along the anteroposterior axis ${ }^{15,26}$ at the germ band elongated stage (3:50-7:20 after fertilization) (Fig. 1b, c; Supplementary Fig. 1), which is maintained throughout Drosophila embryogenesis (Supplementary Fig. 2). We then performed a series of immuno-DNA FISH experiments in embryos at the germ band elongated stage to address $3 \mathrm{D}$ chromatin compaction of Hox clusters. We measured 3D distances between FISH spots for $U b x, a b d A$, and $A b d B$ of the BX-C cluster or lab, Scr, and Antp of the ANT-C cluster. The variation of these inter-spot distances along the anteroposterior axis shows that transcription of each Hox gene correlates with the opening of its corresponding chromatin region, whereas the silenced portion of Hox complexes remains condensed (Fig. 1d-g). For example, when $U b x$ is activated in parasegment 5 (PS5) and PS6, the distances between the $U b x$ and $a b d A$ genes in these PSs were larger than those in the anterior PSs where all BX-C genes are silent. On the other hand, the distance $a b d A-A b d B$ did not increase in PS5-6 and is similar to that of more anterior PS (Fig. 1d), consistent with these two genes being silent in these regions of the embryo. In addition, Hox genes were found closer to Pc foci in PS where they were silenced than in their expression domains (Fig. 1h, i). Consistent with previous observations $\mathrm{s}^{9,27}$, these results indicate that repressed Hox genes are located in Pc foci when they are repressed and outside them when they are expressed. Although ChIP experiments have demonstrated binding of $\mathrm{Ph}$ and $\mathrm{Pc}$ at Hox genes in PS in which they were transcribed ${ }^{28}$, our data show that the $3 \mathrm{D}$ folding of Hox complexes and Hox gene localization within Pc foci matches the Hox gene transcription patterns along the anteroposterior axis.

$\mathrm{Ph}$ and Pc are required to maintain Hox genes silencing. We then performed RNA FISH experiments in null mutant embryos for either the $\mathrm{Ph}\left(p h^{d e l}\right)$ or the Pc $\left(P c^{X T 109}\right)$ subunits. In both mutants, Hox gene derepression started in a few cells, and the proportion of cells with derepression increased during later embryogenesis (Fig. 2; Supplementary Figs. 2-4). Ubx was the first gene of the BX-C cluster to be expressed ectopically in the anterior PS of $p h^{d e l}$ embryos, whereas derepression of $a b d A$ and $A b d B$ started later (Fig. 2a, f-h). Similarly, Antp was the first ANT-C gene to become derepressed in the head of both mutant embryos (Fig. 2i-k), whereas the others were derepressed at later stages (Supplementary Fig. 2). In both mutants, ectopic expression of each Hox gene depended on its position along the anteroposterior axis. For example, the number of cells showing ectopic Ubx expression decreased from PS4 to the anterior PS (Fig. 2a, b; Supplementary Fig. 2q and r), and Scr derepression was stronger in the posterior PS compared with that in the head (Fig. 2j). Taken together these results show that loss of $\mathrm{Ph}$ and $\mathrm{Pc}$ do not result in a general derepression of all Hox genes, although both proteins bind every Hox gene where they are repressed. In addition, ectopic Hox gene transcription was generally stronger and started earlier in $p h^{d e l}$ embryos than in $P c^{X T 109}$ embryos (Supplementary Fig. 2). For example, Ubx and Antp derepression occurred as early as 3:50-4:50 after fertilization in $p h^{d e l}$ embryos, but only after the 4:50-6:00 stage of embryonic development in $P c^{X T 109}$ (Fig. 2f, k). One exception was $A b d B$, which was derepressed earlier in $P c^{X T 109}$ mutants than in $p h^{d e l}$, especially in PS7-PS12 (Fig. 2h; Supplementary Fig. 2w, x). This suggests that different cPRC1 subunits play specific roles on their target chromatin.

Loss of Ph and Pc opens chromatin before transcription. We then tested the possibility that $\mathrm{cPRC} 1$ mediates direct compaction of Hox clusters to prevent ectopic transcription. We reasoned that, if it does so, mutations in $\mathrm{CPRC} 1$ components would affect Hox compaction prior to any detectable transcriptional activation. To test this hypothesis, we performed DNA FISH experiments to monitor chromatin folding of the BX-C and ANT-C loci in cell nuclei of $p h^{d e l}$ and $P c^{X T 109}$ embryos (examples of DNA FISH with three signals from which we measured 3D distances, are shown in Supplementary Figs. 5-7). At the 3:50-4:50 stage after fertilization, distances between $U b x-a b d A, a b d A-A b d B$, and $U b x-a b d B$ were significantly increased in the head and PSO of $p h^{\text {del }}$ mutant embryos compared to those in control embryos (Fig. 3a-c), whereas neither $U b x, a b d A$, nor $A b d B$ were derepressed (Fig. $2 \mathrm{f}-\mathrm{h}$ ). Similar general decompaction effects were 


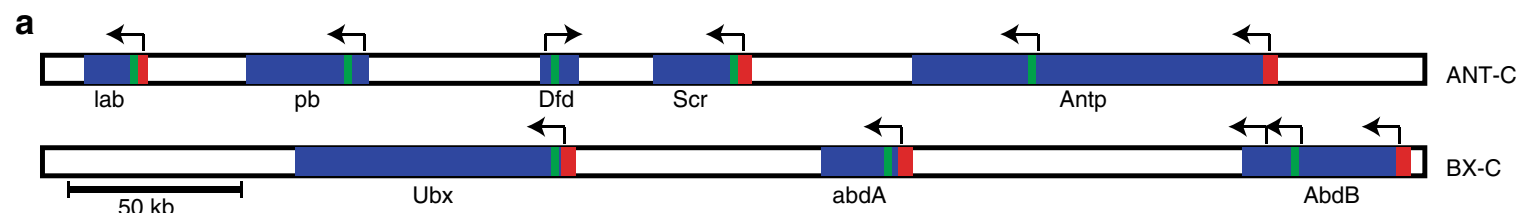

b

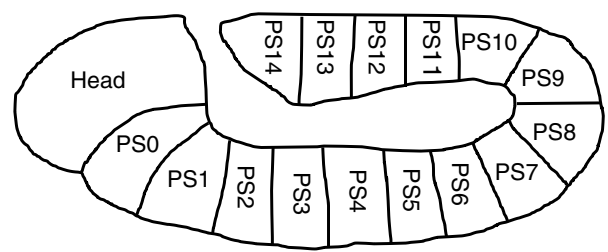

d

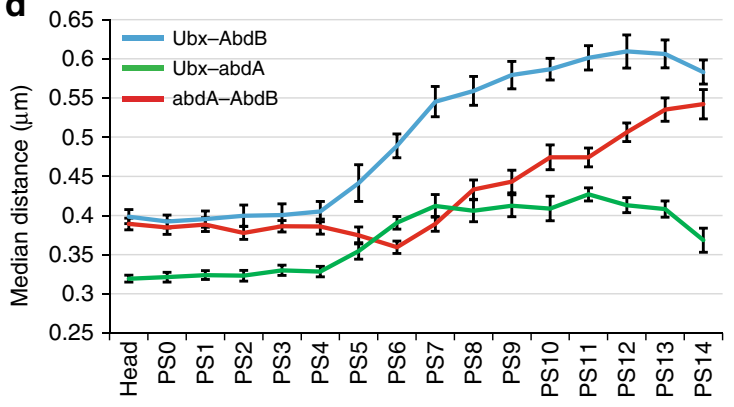

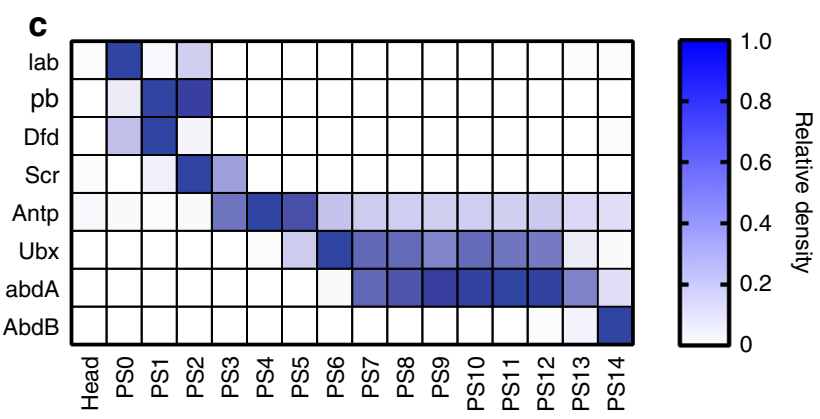

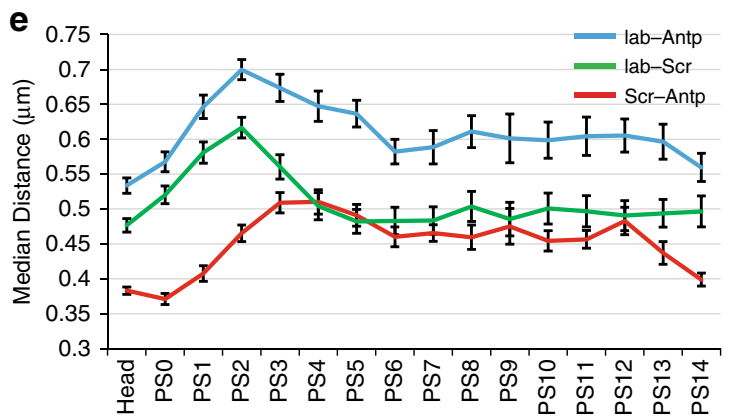

f
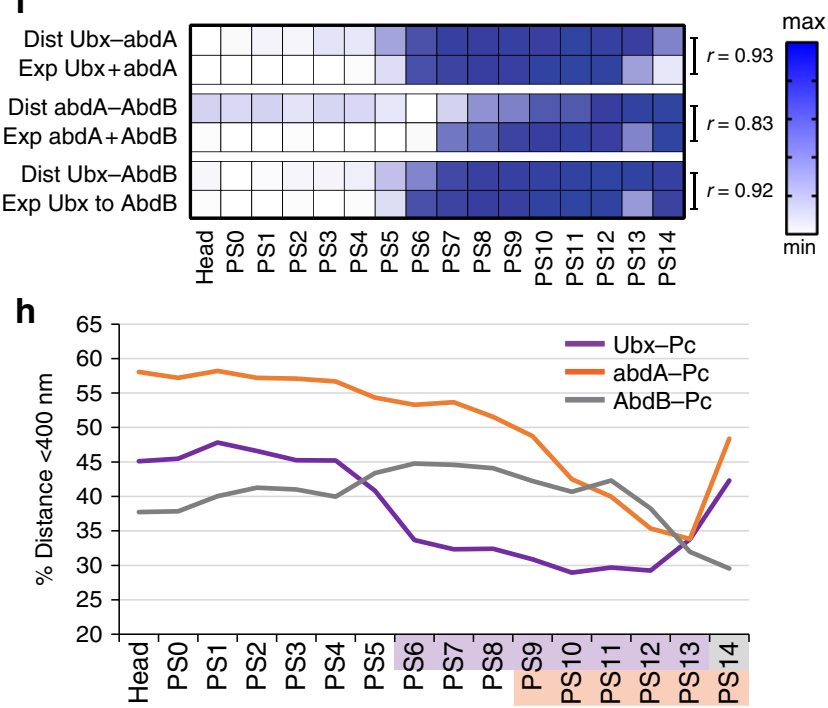

9
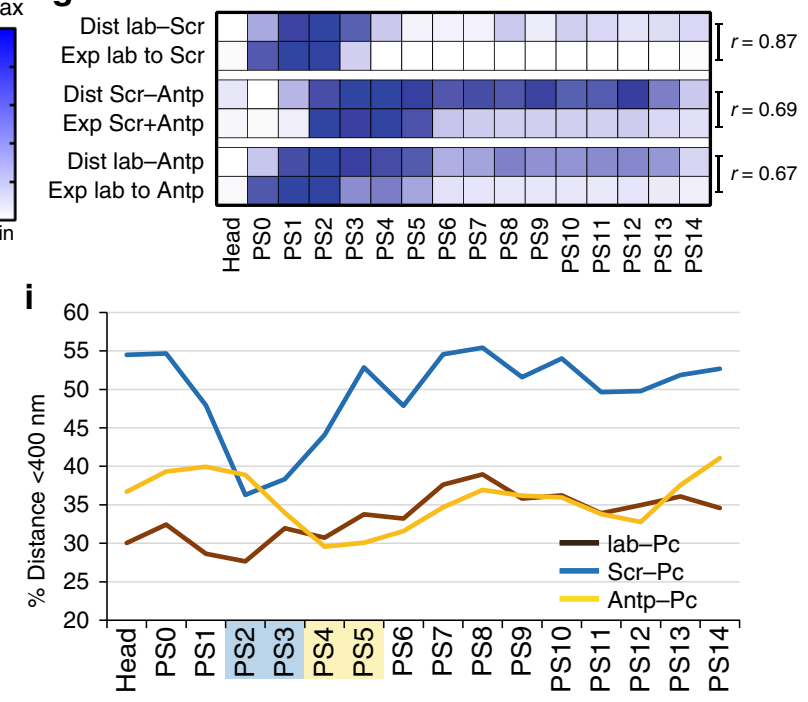

Fig. 1 Hox gene expression correlates with Hox cluster chromatin opening. a Schematic representation of ANT-C and BX-C (Hox genes in blue, positions of DNA FISH probes in red, and positions of RNA FISH probes in green; the arrows show promoters). $\mathbf{b}$ Schematic diagram depicting the PSs of Drosophila embryos in which measurements were performed. c Relative density of RNA FISH spots measured for each Hox gene along the anteroposterior axis of WT Drosophila embryos 3:50-7:20 after fertilization. The density of RNA FISH spots is calculated by dividing the number of spots by the area of the PS. d, e Distances between the promoters of Ubx, $a b d A$, and $A b d B$ (d) or lab, Scr, and Antp (e) measured within cell nuclei of WT Drosophila embryos 3:50-7:20 after fertilization along the anteroposterior axis. We calculated distances between centroids of DNA FISH spots in three dimensions. For each PS of one embryo, we computed the median distances $U b x-a b d A, a b d A-A b d B, U b x-A b d B$ or lab-Scr, Scr-Antp, lab-Antp. Curves represent the average median distances measured in several embryos and the corresponding error bar ( $S E M ; N \geq 16$ ). $\mathbf{f}, \mathbf{g}$ Heat maps showing correlations between Hox gene transcription and chromatin opening in the BX-C (f) and the ANT-C ( $\mathbf{g})$. The physical distance (Dist) between two loci within a Hox complex measured the chromatin opening and Hox gene expression (Exp) is calculated by adding the relative density of RNA FISH spot of Hox genes comprised between these two loci. All measurements were normalized between their minimum and their maximum. $r$ indicates correlation coefficients. $\mathbf{h}$, i Distances between promoters of $U b x, a b d A$, and $A b d B(h)$ or lab, Scr and Antp (i) and the closest Polycomb foci were measured in WT Drosophila embryos 3:50-7:20 after fertilization. The percentage of distances measuring less than $400 \mathrm{~nm}$ was calculated for each PS of one embryo. Curves represent the mean percentage measured in several embryos. The highlighted PSs show regions wherein Hox genes were found to be significantly further away from Pc foci than in HeadPSO ( $t$-test, one-tailed, $P<0.01$; Ubx in violet, $a b d A$ in orange, and AbdB in gray; Scr in blue and Antp in yellow) 

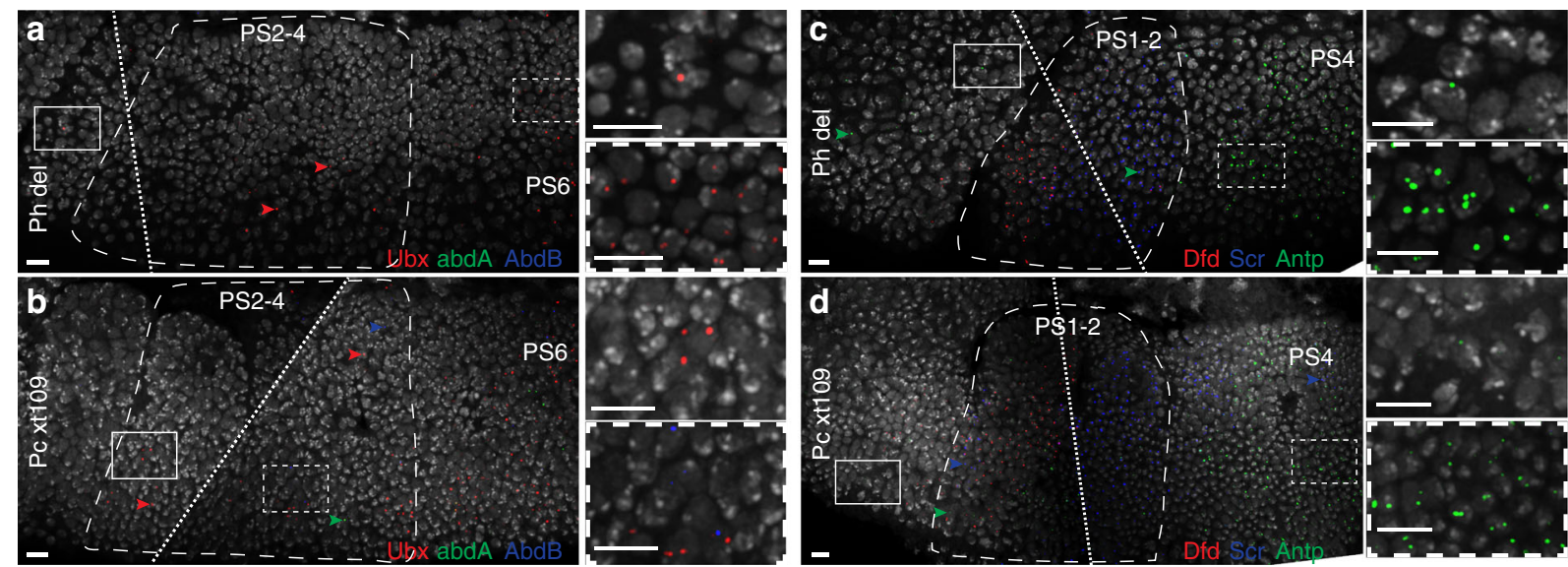

e

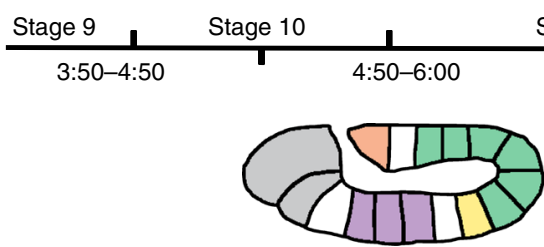

f

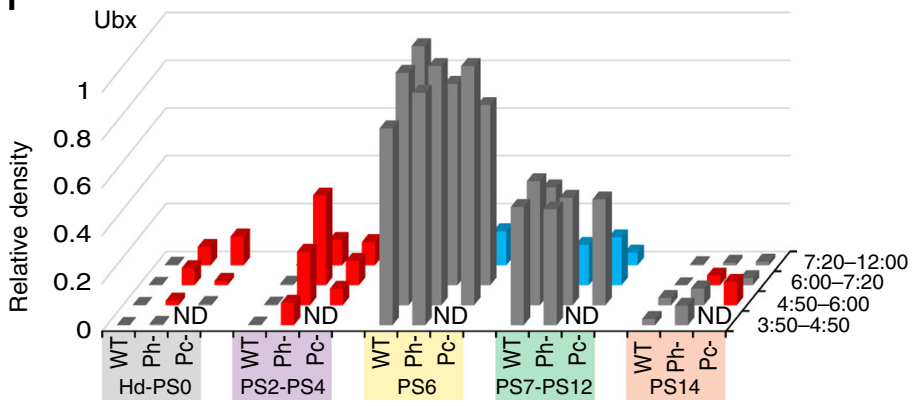

g

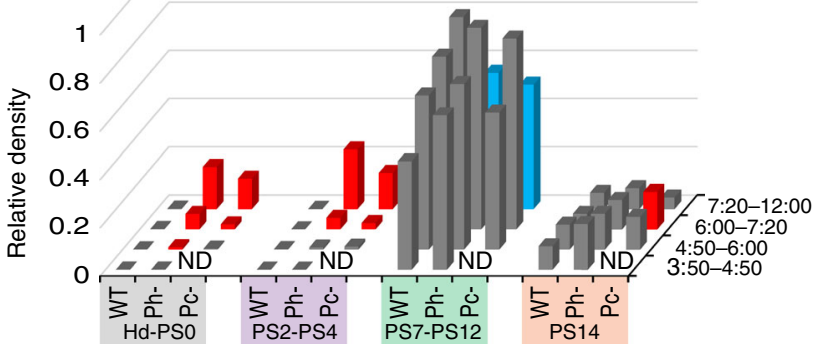

h

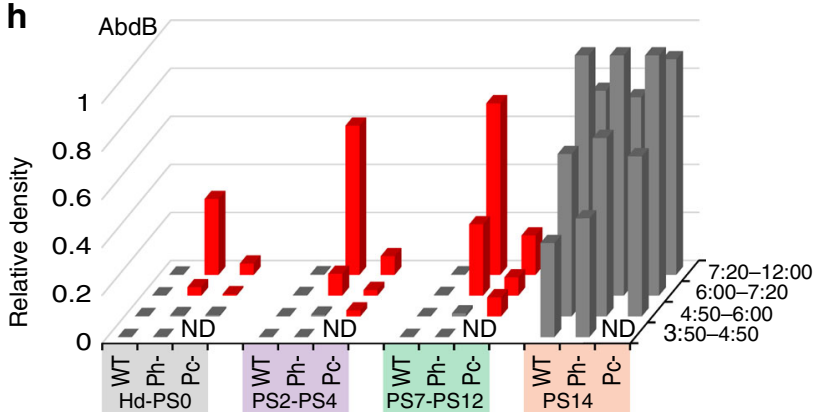

Stage 12

Stage 13 7:20-12:00

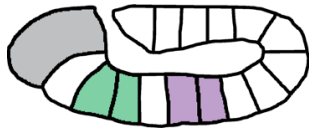

i

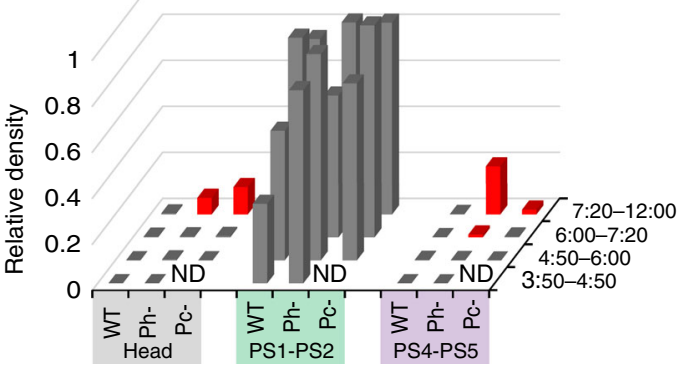

j

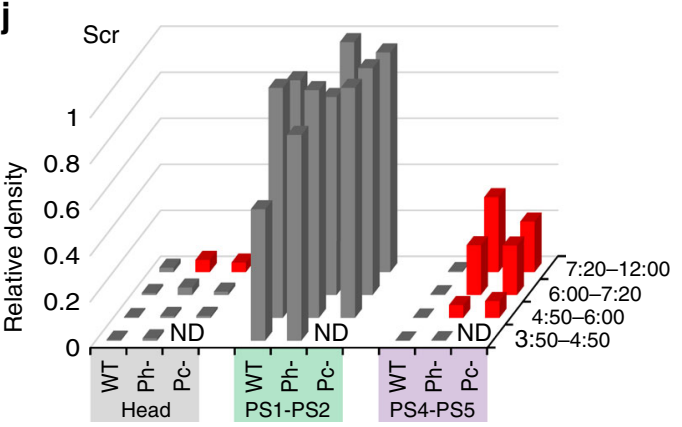

k

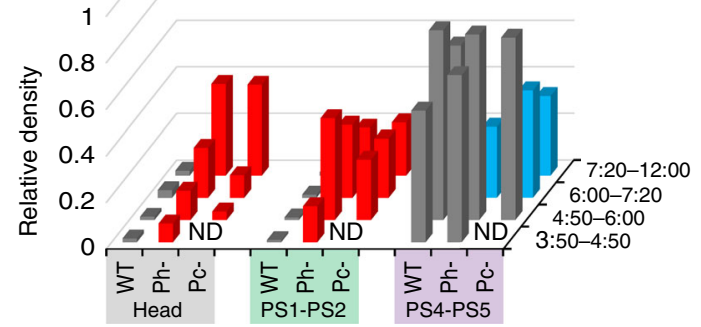


Fig. 2 Timing of Hox gene derepression in $P h^{\text {del }}$ and $P C^{X T 109}$ embryos. a-d RNA FISH images illustrating the earliest ectopic Hox gene expression observed in $p h^{\text {del }}(\mathbf{a}, \mathbf{c})$ and $P_{C}^{X T 109}(\mathbf{b}, \mathbf{d})$ embryos. These images are maximum intensity projections of confocal images and dashed lines indicate where two images were merged. Arrowheads indicate few cells showing Hox gene transcription outside of their domains of expression (Ubx: red in $\mathbf{a}$, $\mathbf{b}$; $a b d A$ : green in

b; AbdB: blue in b; Antp: green in c, $\mathbf{d}$ and Scr: blue in $\mathbf{d})$. Scale bars, $10 \mu \mathrm{m}$. e Embryos were grouped into four classes based on their developmental stage, which depended on the duration of their development after fertilization at $25^{\circ} \mathrm{C}$. $\mathbf{f}-\mathbf{k}$, Relative densities of RNA FISH spots corresponding to Ubx (f), abdA $(\mathbf{g}), A b d B(\mathbf{h}), p b(\mathbf{i}), \operatorname{Scr}(\mathbf{j})$, and Antp (k) expression measured in WT, Phdel and PC XT109 embryos during development. For simplicity, PSs wherein Hox genes of BX-C (f-h) and ANT-C (i-k) behave similarly were grouped (complete data are shown in Supplementary Figure 2). Red columns indicate where and when Hox gene transcription was significantly ectopically expressed in the mutants compared to WT embryos, whereas the blue columns show significant (Mann-Whitney U-test, two-tailed, $P<0.01$ ) downregulation of Hox gene transcription

observed in PS2-PS4 (Fig. 3g-i), although $a b d A$ and $A b d B$ are repressed and $U b x$ is derepressed only in a few cells of $p h^{\text {del }}$ embryos (Fig. 2f). Despite a weaker effect of Pc on BX-C folding, $P C^{X T 109}$ mutant embryos displayed significantly greater $U b x-$ $a b d A, a b d A-A b d B$, and $U b x-a b d B$ distances than those of control embryos in PS2-PS4 at the 3:50-4:50 stage of development (Fig. 3g-i), without derepression of $U b x$, $a d b A$, and $A b d B$ (Fig. $2 \mathrm{f}-\mathrm{h}$ ). Similarly, $\mathrm{Ph}$ and $\mathrm{Pc}$ were both required to globally compact ANT-C in the heads of embryos from the 3:50-4:50 stage after fertilization (Fig. 4a-c), whereas Antp was the only Hox gene of the ANT-C cluster to be derepressed, and this occurred only in $p h^{d e l}$ mutants (Fig. $2 \mathrm{i}-\mathrm{k}$ ). These results show that in PSs where every Hox gene of one complex is repressed, the first effect of $\mathrm{Ph}$ and $\mathrm{Pc}$ on Hox clusters folding can be detected before ectopic Hox genes transcription. Moreover, loss of Ph and Pc results in decondensation of the whole Hox clusters, whereas the first effects on Hox genes derepression affected a minority of the cells and onlys a few Hox genes.

To compare $\mathrm{Ph}$ and $\mathrm{Pc}$, we plotted the effect of $p h$ or $P c$ deletions on distances measured within the BX-C (Fig. 3d-f; j-l) or the ANT-C (Fig. 4d-f) during embryogenesis. After the 4:50-6:00 stage, the effect of both proteins on BX-C folding progressively increased (Fig. $3 \mathrm{~d}-\mathrm{f} ; \mathrm{j}-\mathrm{l}$ ) with a timing matching the ectopic expression of $a b d A$ and $A b d B$ (Fig. 2g-h). At 7:20-12:00 h after fertilization, both mutant embryos showed a stronger opening of the BX-C in the head-PS0 (Fig. 3a-c) and PS2-PS4 (Fig. 3g-i). To summarize these effects, we plotted the three median distances between the promoters of $U b x, a b d A$, and $A b d B$ (Fig. 3m-p) or between lab, Scr, and Antp (Fig. 4g-j). During early embryogenesis, the effects of the loss of $\mathrm{Ph}$ and $\mathrm{Pc}$ on Hox cluster folding were significant (Figs. $3 \mathrm{a}-\mathrm{c}, \mathrm{n} ; 4 \mathrm{a}-\mathrm{c}, \mathrm{h}$ and Supplementary Fig. 8a-f). A stronger decompaction was observed in later embryogenesis (Fig. 3a-c, o; $4 \mathrm{a}-\mathrm{c}$, i and Supplementary Fig. $8 \mathrm{~g}-\mathrm{l})$, consistent with strong ectopic Hox expression. These late effects coincide with the pattern of distance changes observed during physiological Hox activation in the appropriate PSs (Figs. 3p, 4j). Therefore, the strong effects on Hox distances observed in late development in the mutants is most likely due to the effect of ectopic transcription. Taken together, these results demonstrate that the effects of loss of PRC1 on condensation of Hox cluster chromatin precede transcriptional derepression. Therefore, chromatin opening in the mutants is not a consequence of transcription, suggesting that the primary function of PRC1 is to establish a compact architecture in cells where Hox loci are silenced.

$\mathrm{Ph}$ and Pc only compact silenced Hox genes. Since PRC1 was shown to bind to Hox genes also when they are active ${ }^{28,29}$, we wondered whether the loss of PRC1 components would affect the higher-order organization of active Hox genes. To this aim, we investigated the consequences of $P c$ - or $p h$-null mutations on Hox loci. RNA FISH analysis did not reveal changes in Hox gene expression within their normal expression domains during early embryogenesis (3:50-6:00 after fertilization) (Fig. 2f-k). We then analyzed chromatin compaction from DNA FISH data. In PS9-PS12, where $U b x$ and $a b d A$ are expressed but $A b d B$ is silent in the WT, no significant effect on the $U b x-a b d A$ distance was observed. However, as expected, the $a b d A-A b d B$ distance was increased in both $p h^{d e l}$ and $P_{c}^{X T 109}$ embryos compared to control embryos (Fig. 5a, b). Conversely, the distance $a b d A-A b d B$ was not increased in PS14 where only $A b d B$ is expressed, while the distance $U b x-a b d A$ increased in both mutants during embryogenesis (Fig. 5c, d). Similarly, in the absence of $\mathrm{Ph}$ or Pc, the distance between the lab-Scr genes was significantly increased in PS4-PS5, where Hox genes located between lab and Scr are repressed in WT embryos (Fig. 5e, f). These results demonstrate that $\mathrm{Pc}$ and $\mathrm{Ph}$ compact chromatin fibers encompassing Hox genes only in cells in which they are normally repressed (Supplementary Figs. 9-10).

The fact that Pc was found to have a weaker effect than $\mathrm{Ph}$ on Hox clusters folding in the PSs where every Hox gene of each complex is repressed (Figs. 3 and 4) suggests that the two proteins might elicit different functions in CPRC1-dependent higher-order chromatin folding. We thus analyzed the nuclear distribution of each of the proteins in the presence of a null mutation in the other component. While the nuclear Pc distribution became diffuse in $p h^{d e l}$ embryos, $\mathrm{Ph}$ still accumulated in nuclear foci in $P c^{X T 109}$ embryos (Supplementary Fig. 11a-f). Furthermore, immuno-FISH experiments using anti-Ph and anti-Pc antibodies and FISH probes recognizing either $a b d A$ or $S c r$ showed that $\mathrm{Ph}$ protein still accumulated at $a b d A$ and $S c r$ loci in $\mathrm{Pc}^{\mathrm{XT} 109}$ embryos, although its enrichment was weaker than in control embryos. This contrasts with the nuclear distribution of Pc, which did not accumulate on $a b d A$ and $S c r$ in $p h^{d e l}$ embryos (Fig. 5g, h; Supplementary Fig. 11g, h). These data suggest that Ph retains ability to form higher-order structures in the absence of $\mathrm{Pc}$ to a greater extent than does $\mathrm{Pc}$ in the absence of Ph. Finally, we analyzed whether the degree of chromatin compaction induced by each of the proteins correlates with its effects on gene silencing. To this aim, for each PS where $a b d A$ or $A b d B$ is repressed in WT embryos, we calculated the difference of $a b d A$ or $A b d B$ expression between $p h^{d e l}$ and $P c^{X T 109}$ mutant embryos at stage 4:50-6:00. Scatterplots between these values and the difference of distance $a b d A-A b d B$ between $p h^{d e l}$ and $P c^{X T 109}$ mutant embryos at stage 3:50-4:50 showed a clear correlation between chromatin opening in early development and the subsequent ectopic transcription (Fig. 5i, j). These data suggest a causal link between chromatin condensation and gene silencing.

\section{Discussion}

Our data indicate that deleting PRC1 components induces higher-order chromatin decompaction prior to ectopic transcription, suggesting that chromatin opening is not a consequence of transcription. This conclusion is valid in the assumption that RNA FISH is sensitive enough to detect the first events of ectopic gene expression. Several data suggest this to be the case. First, in 
a
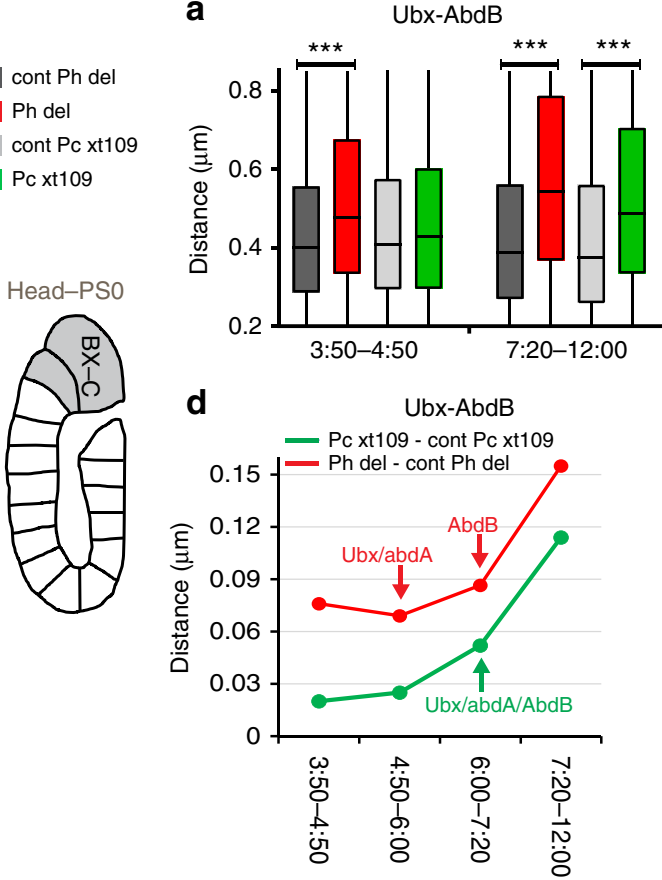

g

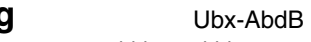

cont Ph del Ph del cont Pc xt109 Pc xt109
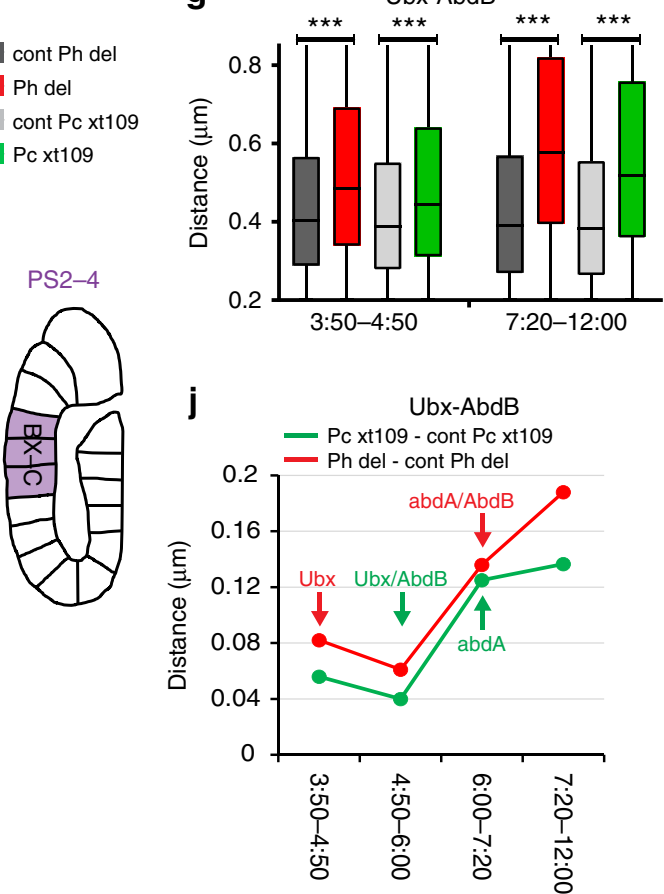

b

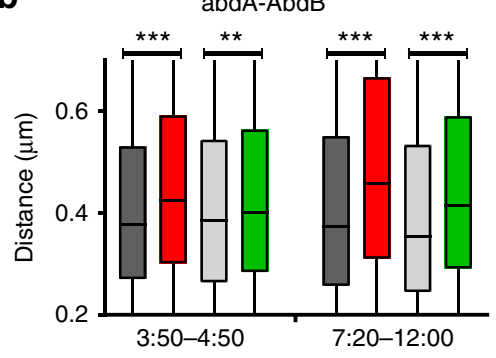

e

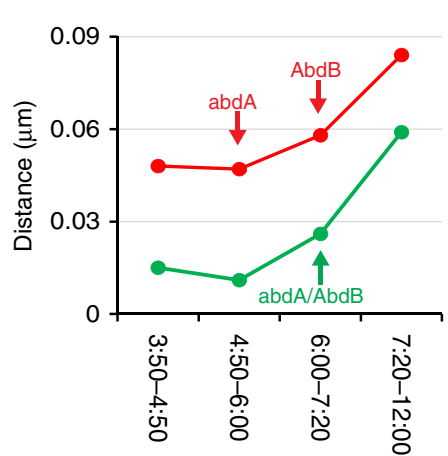

h

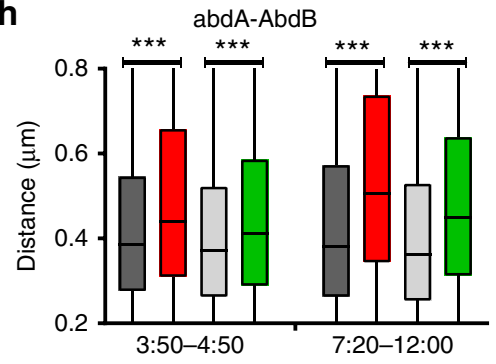

k

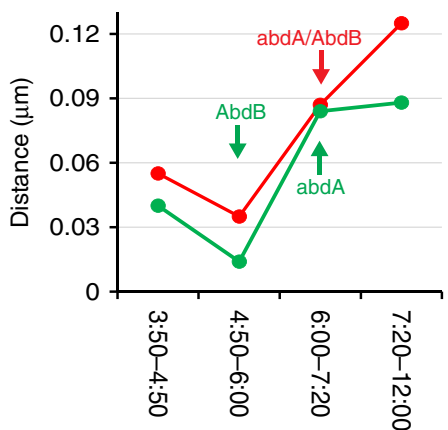

c

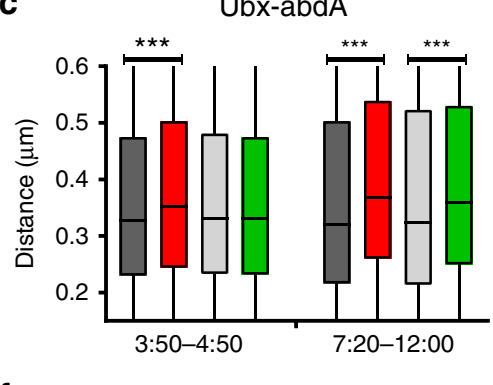

f

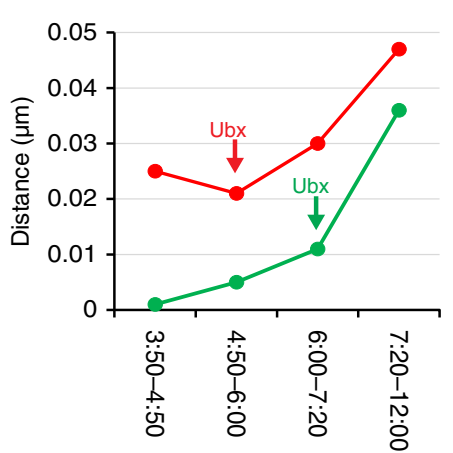

i

Ubx-abdA

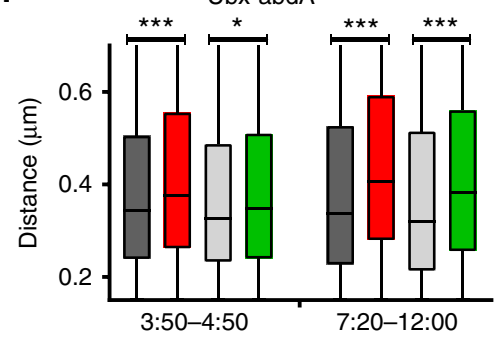

I

Ubx-abdA

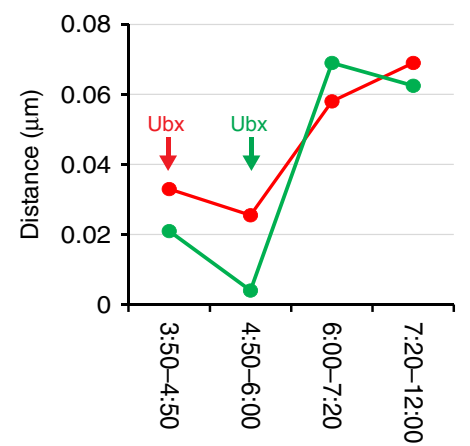

AbdB

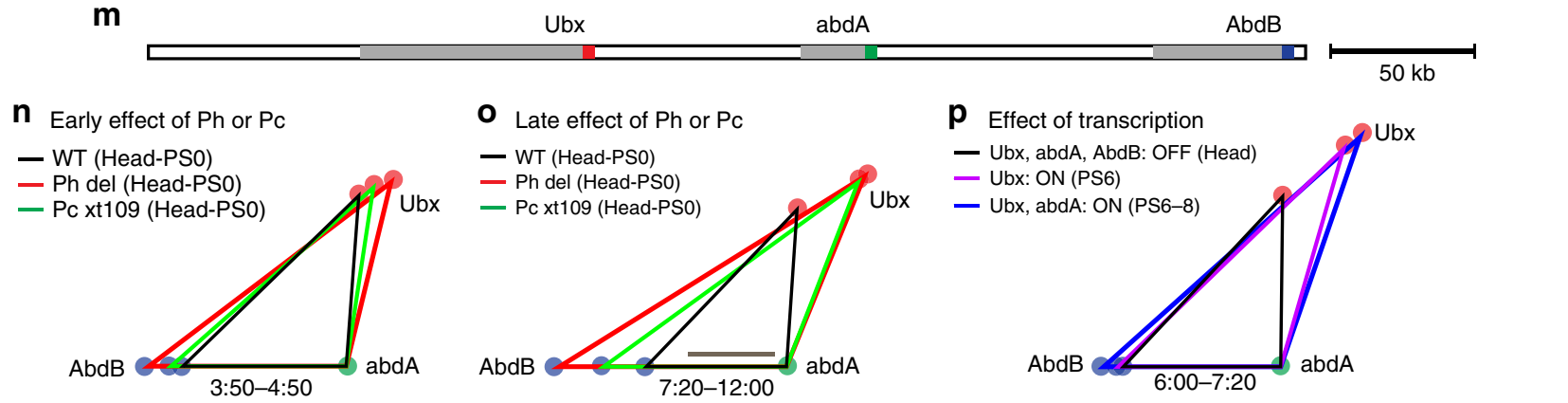


Fig. $3 \mathrm{Ph}$ and $\mathrm{Pc}$ are required to compact repressed $\mathrm{BX}-\mathrm{C}$ before ectopic Hox gene transcription. a-c; $\mathbf{g}-\mathbf{i}$ Box plots displaying distributions of the distances $\operatorname{Ubx}-\operatorname{AbdB}(\mathbf{a}, \mathbf{g}), a b d A-A b d B(\mathbf{b}, \mathbf{h}), U b x-a b d A(\mathbf{c}, \mathbf{i})$, in the head-PSO (a-c), and in PS2-PS4 (g-i) during early and late embryogenesis. Distances were measured in the cell nuclei of ph ${ }^{\text {del }}$ embryos (red) and their respective controls (dark gray) or Pc XT109 embryos (green), and their respective controls (light gray). Distance distributions are comprised between 0 and $1.5 \mu \mathrm{m}$ and the lower and upper bounds of the colored rectangles correspond to the first and third quartiles, whereas the middle bars show the median distances. The black lines indicate significant differences between the mutants and their respective control embryos (Mann-Whitney $U$-test, two-tailed, ${ }^{\star} P<0.05 ;{ }^{\star \star} P<0.01 ;{ }^{\star \star \star} P<0.001$ ). $\mathbf{d}-\mathbf{f} ;$; $\mathbf{j}-\mathbf{I}$ Difference between the median distances Ubx$A b d B(\mathbf{d}, \mathbf{j}), a b d A-A b d B(\mathbf{e}, \mathbf{k}), U b x-a b d A(\mathbf{f}-\mathbf{I})$ measured in $p h^{d e l}$ and the same distances measured in its control embryos (red) or in $P c \times T 109$ and its control embryos (green), during embryonic development in head-PSO (d-f) and PS2-PS4 (j-I). Arrows indicate when a Hox gene is firstly ectopically expressed in $p^{\text {del }}$ (red) or P $^{X T 109}$ (green) embryos. $\mathbf{m}$ Schematic linear representation of BC-X showing the DNA FISH probe positions. $\mathbf{n}-\mathbf{p}$ Plots of the three median distances corrected for chromatic aberrations, between the promoters of $U b x, a b d A$, and $A b d B$. Comparison of the effects of Ph and Pc on the folding of BX$C$ during early $(n)$ and late embryogenesis (o) with the openings induced by Hox gene transcription (p). Scale bar, $100 \mathrm{~nm}$

order to detect early Hox genes transcription we used RNA FISH experiments with probes located in the first intron, i.e. we should be able to detect nascent transcripts within few minutes from the first productive event. Indeed, we observed RNA FISH signal in most of the cells inside embryonic areas where one Hox gene is expressed (Supplementary Fig. 1), indicating that this approach is sensitive and efficient. Furthermore, we identified ectopic Hox genes expression at earlier developmental stage compared to previous reports ${ }^{30,31}$. Similarly, we detected expression of dachshund in embryos at developmental stage 5 and vestigial at germ band extended stage (Supplementary Fig. 12a-b), in both cases earlier than previously reported ${ }^{32,33}$ and corresponding to barely detectable transcription also using high-throughput approaches. Therefore, we believe that our RNA-FISH procedure readily detects low levels of gene expression. We also note that, while initial loss of silencing is detected in few cells of the corresponding PS, chromatin opening was generally observed in the whole embryonic region where each gene is normally silenced. Taken together, these results strongly indicate that cPRC1 compacts Hox clusters via the formation of higher-order chromosome structures during early Drosophila embryogenesis (Fig. 5k and Supplementary Movie 1). We thus propose that the absence of chromatin compaction in PcG mutant embryos does not directly trigger loss of silencing, but rather allows sequencespecific transcription factors to regulate Hox genes during later embryogenesis. The interplay between the general chromatin opening upon deletion of PRC1 and the identity and concentration of transcription factors that are able to bind to each of the Hox gene regulatory elements would ultimately determine the time and space of ectopic expression for each of the genes. For example, Hunchback has been shown to directly repress $\mathrm{Ubx}^{34}$ and we observed a gradient of derepression of Ubx which is opposite to the Hunchback gradient. Therefore, we can speculate that the decrease of Hunchback expression during mid-embryogenesis, in conjunction with loss of PRC1, causes the observed pattern of ectopic Ubx expression in PcG mutant embryos.

We note that, during late embryogenesis when ectopic Hox gene expression occurs in some cells of one PS, an alternative approach to reveal chromatin opening in cells showing Hox gene derepression would be to combine DNA and RNA FISH experiments. However, applying this approach during early embryogenesis, which is the critical experiment in the present work, would not improve our results, since no cells show ectopic Hox gene expression at this developmental stage. Furthermore, in order to address Hox gene localization compared to $\mathrm{Pc} / \mathrm{Ph}$ foci we used confocal microscopy. This approach allows us to study relative changes in distances between loci and Pc foci along the $\mathrm{A} / \mathrm{P}$ axis, but its precision is limited. In future studies, it would be interesting to use super-resolution microscopy in order to measure the exact distance distributions. Despite these limitations, our results clearly indicate that the roles of the $\mathrm{Ph}$ and $\mathrm{Pc}$ proteins in the formation of PRC1 foci and Hox gene silencing are not equivalent, with $\mathrm{Ph}$ showing stronger effects, except on the $a b d A$ and $A b d B$ region of the BX-C. Since both $\mathrm{Ph}$ and $\mathrm{Pc}$ proteins were not detected in mutant $\mathrm{Ph}^{\text {del }}$ and $\mathrm{Pc}^{\mathrm{xt} 109}$ embryos from 3:50-4:50 stage after fertilization, it is unlikely that this difference results from maternal effects. In addition, a stronger maternal deposition of $\mathrm{Pc}$ or $\mathrm{Ph}$ could not explain why $\mathrm{Ubx}$ is derepressed later in $P c^{X T 109}$ than in $p h^{\text {del }}$ embryos, whereas the reverse is observed for $A b d B$. One possible explanation is that, in the absence of Pc and of its chromo domain, cPRC1 might only lose its anchoring to $\mathrm{H} 3 \mathrm{~K} 27 \mathrm{me} 3$ while retaining some of its ability to bind discrete target regulatory elements and mediate their clustering through oligomerization of $\mathrm{Ph}^{7,9,35}$ (Supplementary Fig. $12 \mathrm{c}-\mathrm{d})^{36}$. The effects of $P c$ deletion would thus depend on the levels of $\mathrm{H} 3 \mathrm{~K} 27 \mathrm{me} 3$ at each locus and, indeed, H3K27me3 levels are highest in the $a b d A-A b d B$ region of the BX-C compared to all others $^{28}$. On the other hand, in the absence of Ph, cPRC1 is expected to lose its ability to form higher-order structures through oligomerization, therefore inducing strong decompaction throughout the BX-C and ANT-C and, consequently, a strong loss of silencing. Further studies will be required to elucidate this point and the mechanism of PRC1-mediated silencing at other genes. In particular, it will be interesting to test whether the role of PRC1 in chromatin condensation is predominant at large Pc domains containing many PRC1-binding sites and whether the mechanisms of silencing differ at smaller target loci, both in Drosophila and in mammals.

\section{Methods}

Fly lines and embryo fixation. The Oregon-R w[1118] line was used as the WT control line. The $p h^{\text {del }}$ stock is a null mutant ${ }^{37}$ and was balanced over the KrGFP$F M 7 c$ balancer (FKG: obtained from BL\#5193 of the Bloomington Drosophila Stock Center). The $P c^{X T 109}$ stock is a null mutant ${ }^{38}$ and was balanced over the KrGFPTM3, Sb balancer (TKG: obtained from BL\#5195 of the Bloomington Drosophila Stock Center). Flies were maintained on standard cornmeal yeast extract media at $21^{\circ} \mathrm{C}$. Embryos were harvested on agar/vinegar plates. Embryos were fixed according to the protocol described by Bantignies and Cavalli ${ }^{39}$. Briefly, embryos were dechorionated with bleach for $5 \mathrm{~min}$ and transferred into a glass flask, followed by addition of $5 \mathrm{ml}$ of fixation buffer containing: $4 \%$ paraformaldehyde, $\mathrm{KCl}$ (60 mM), $\mathrm{NaCl}(15 \mathrm{mM})$, spermidine $(0.5 \mathrm{mM})$, spermine $(0.15 \mathrm{mM})$, EDTA $(2 \mathrm{mM})$, EGTA $(0.5 \mathrm{mM})$, PIPES $(15 \mathrm{mM})$, and $5 \mathrm{ml}$ of heptane. Embryos were fixed under vigorous agitation on mini-shaker for $25 \mathrm{~min}$. The aqueous phase was then removed and $5 \mathrm{ml}$ of methanol was added. After shaking for $1 \mathrm{~min}$, fixed embryos were collected at the bottom of the glass flask and stored in methanol at $-20^{\circ} \mathrm{C}$.

RNA FISH. RNA FISH experiments were performed according to the protocol described by Kosman et al. ${ }^{26}$. Probes were prepared using a direct labeling approach with a FISH Tag RNA Kit (Thermo Fisher Scientific, F32956), and primers used to synthesize RNA probes are listed in Supplementary Table 1. We used three fluorochromes: A488 ( $\sim 14 \mathrm{pmol} / \mu \mathrm{l}$ for a RNA concentration of $\sim 75 \mathrm{ng} / \mu \mathrm{l})$, A555 ( $\sim 3.4 \mathrm{pmol} / \mu \mathrm{l}$ for a RNA concentration of $\sim 50 \mathrm{ng} / \mu \mathrm{l})$, and A647 $(\sim 2.3 \mathrm{pmol} /$ $\mu \mathrm{l}$ for a RNA concentration of $\sim 35 \mathrm{ng} / \mu \mathrm{l})$. Briefly, embryos were transferred from methanol to ethanol and then incubated for $1 \mathrm{~h}$ in $90 \%$ xylene/10\% ethanol. After being washed sequentially in ethanol and methanol, embryos were incubated for $25 \mathrm{~min}$ in $\mathrm{PBS}+0.1 \%$ tween $(\mathrm{PBT})+5 \%$ formaldehyde. After being washed in PBT, the embryos were treated with a solution of proteinase $\mathrm{K}(10 \mu \mathrm{g} / \mathrm{ml})$ in PBT for 5-6 min. This reaction was terminated by washing the embryos in PBT. A 


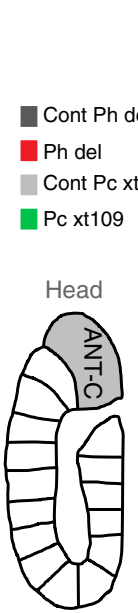

a

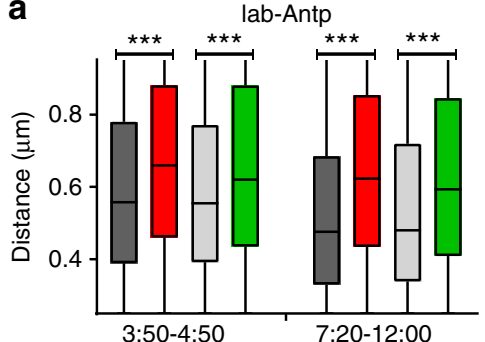

d

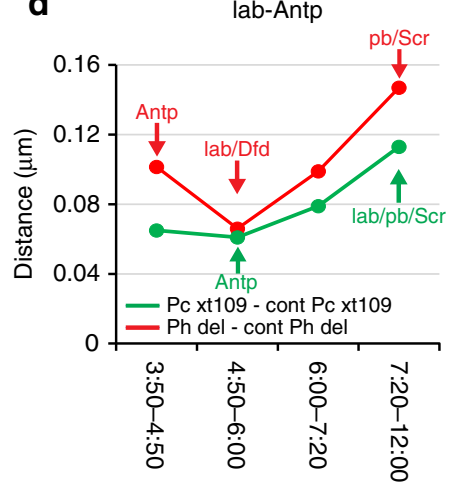

b

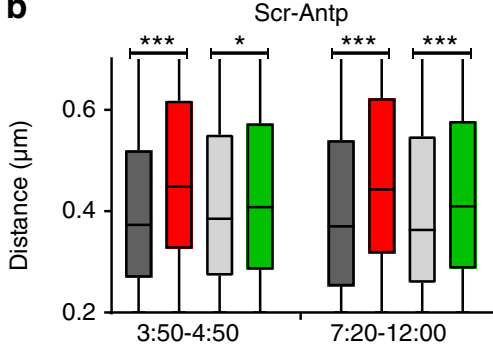

e

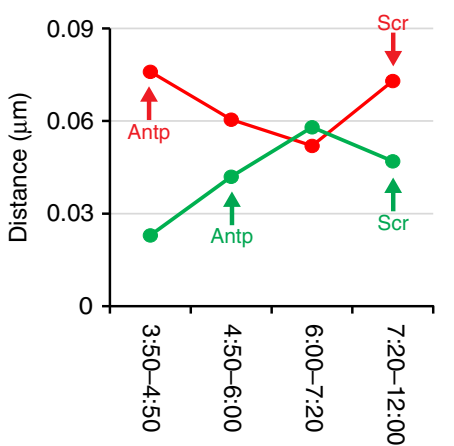

C

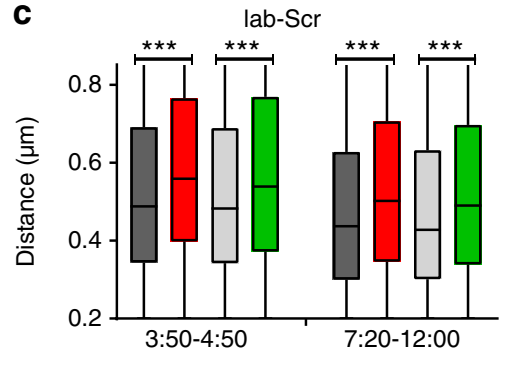

f

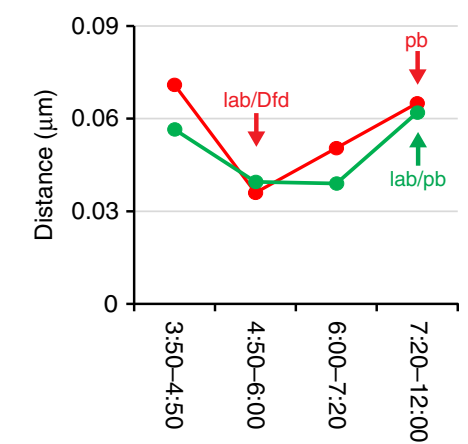

lab-Scr

Antp

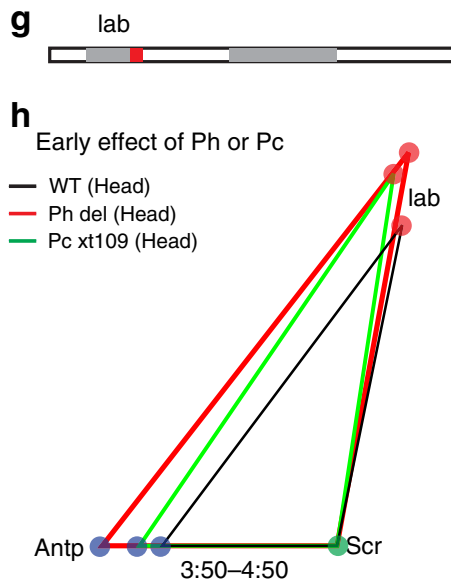

Scr

(2)

$50 \mathrm{~kb}$

i

Late effect of $\mathrm{Ph}$ or $\mathrm{Pc}$

\section{— WT (Head) \\ - Ph del (Head)}

— Pc xt109 (Head)

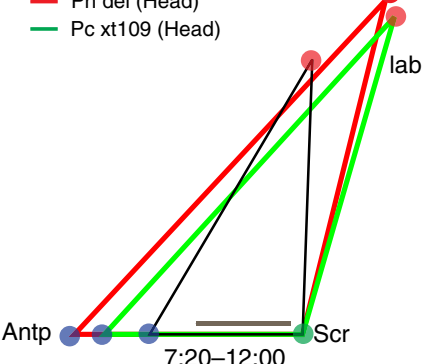

\section{I}

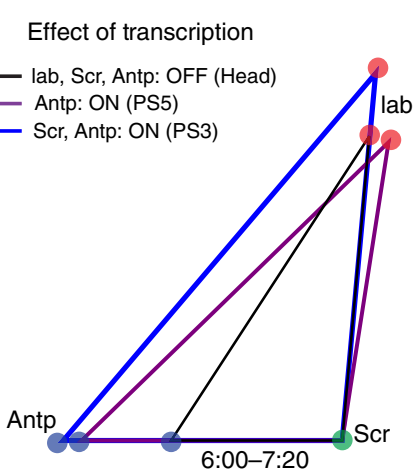

Fig. $4 \mathrm{Ph}$ and $\mathrm{Pc}$ are required to compact repressed ANT-C before ectopic Hox gene transcription. a-c Box plots displaying distributions of the distances: lab-Antp (a), Scr-Antp (b) and lab-Scr (c) in the head during early and late embryogenesis. Distances were measured in the cell nuclei of ph ${ }^{d e l}$ embryos (red) and their respective controls (dark gray) or $P_{C}^{X T 109}$ embryos (green) and their respective controls (light gray). Distance distributions are comprised between 0 and $1.5 \mu \mathrm{m}$ and the lower and upper bounds of the colored rectangles correspond to the first and third quartiles, whereas the middle bars show the median distances. The black lines indicate significant differences between the mutants and their respective control embryos (Mann-Whitney $U$-test, two-tailed, $\left.{ }^{\star} P<0.05 ;{ }^{\star \star} P<0.01 ;{ }^{\star \star \star} P<0.001\right)$. d-f Difference between the median distances lab-Antp (d), Scr-Antp (e), and lab-Scr (f) measured in ph ${ }^{d e l}$ and the same distances measured in its control embryos (red) or in $P_{C} X T 109$ and its control embryos (green) during embryonic development in head. Arrows indicate when a Hox gene is firstly ectopically expressed in ph ${ }^{\text {del }}$ (red) or Pc ${ }^{X T 109}$ (green) embryos. g Schematic linear representation of ANT-C showing the DNA FISH probe positions. h-j Plots of the three median distances corrected for chromatic aberrations, between the promoters of lab, Scr, and Antp. Comparison of the effects of Ph and Pc on the folding of ANT-C inside cell nuclei during early (h) and late embryogenesis (i) with the openings induced by Hox gene transcription (j). Scale bar, $100 \mathrm{~nm}$

second post-fixation step was then performed with $\mathrm{PBT}+5 \%$ formaldehyde for $25 \mathrm{~min}$. After being washed in PBT, embryos were transferred to a hybridization solution ( $50 \%$ formamide, $5 \times \mathrm{SSC}, 100 \mu \mathrm{g} / \mathrm{ml}$ tRNA, $50 \mu \mathrm{g} / \mathrm{ml}$ heparin, and $0.1 \%$ Tween), and pre-hybridization was performed for $1 \mathrm{~h}$ at $55^{\circ} \mathrm{C}$. Finally, embryos were hybridized for $16-20 \mathrm{~h}$ at $55^{\circ} \mathrm{C}$ with labeled probes followed by extensive washes. Typically, we added $1.2 \mu \mathrm{l}$ of three probes containing either A488, A555, or A647 to $50 \mu$ of hybridization buffer. DAPI staining was performed before mounting the embryos in Vectashield (Eurobio, H-1000) between a slide and coverslip.

RNA FISH experiments were performed on embryos collected from Oregon-R

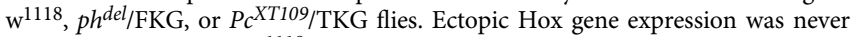
observed in Oregon- $\mathrm{R} \mathrm{w}^{1118}$ embryos, whereas $\sim 25 \%$ of the embryos issued from $\mathrm{Ph}$ del/FKG crosses showed ectopic expression of Ubx or Antp from developmental stage 9 through later embryogenesis and corresponded to $p h^{\text {del }}$ mutant embryos. Similarly, $\sim 25 \%$ of the embryos issued from $P c^{X T 109} /$ TKG crosses showed ectopic expression of $U b x, A b d B$, or Antp at developmental stage 10 through later embryogenesis and corresponded to $P c^{X T 109}$ mutant embryos. Both balancer chromosomes FKG and TKG did not affect Hox genes expression since no difference have been observed between WT, $\mathrm{Ph}^{\mathrm{del}}$ control, and $\mathrm{Pc}^{\mathrm{xt} 109}$ control embryos.

Immuno-DNA FISH and immuno-localization. Immuno-DNA FISH experiments were performed according to the protocol described by Bantignies and Cavalli ${ }^{39}$. Briefly, to re-hydrate fixed embryos, we used a series of methanol/PBS $+0.1 \%$ tween (PBT) solutions: 100/0; 90/10; 70/30; 50/50; 30/70; 0/100. Embryos were then incubated in a solution of RNAseA $(200 \mu \mathrm{g} / \mathrm{ml})$ in PBT for $2 \mathrm{~h}$. After an additional $2 \mathrm{~h}$ incubation in PBS $+0.2 \%$ triton $\mathrm{X}-100$ (PBTr), embryos were progressively transferred in pre-hybridization mixture (pHM) containing $50 \%$ formamide, $4 \times \mathrm{SSC}, 100 \mathrm{mM} \mathrm{NaH}_{2} \mathrm{PO}_{4}$, and $0.1 \%$ tween. Embryos were incubated 


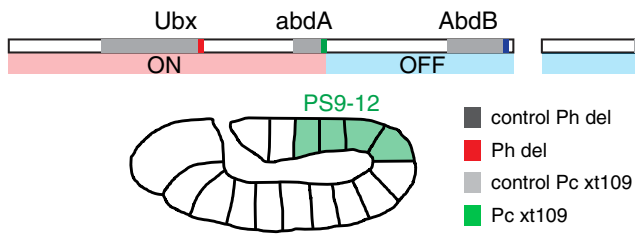

a

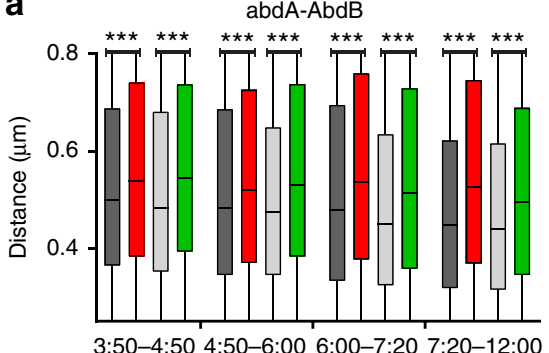

b

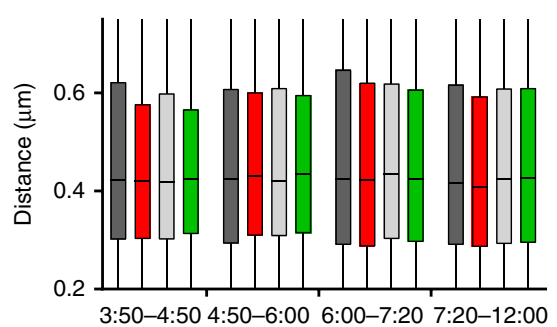

g

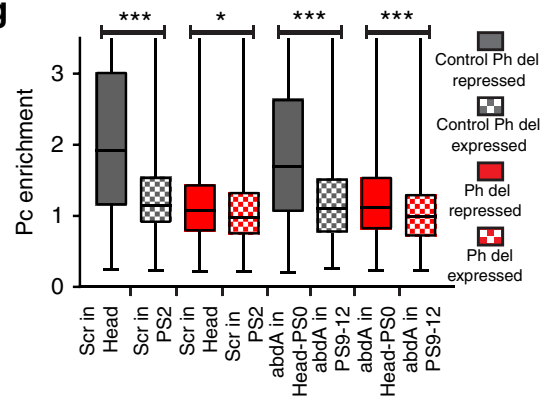

h
C

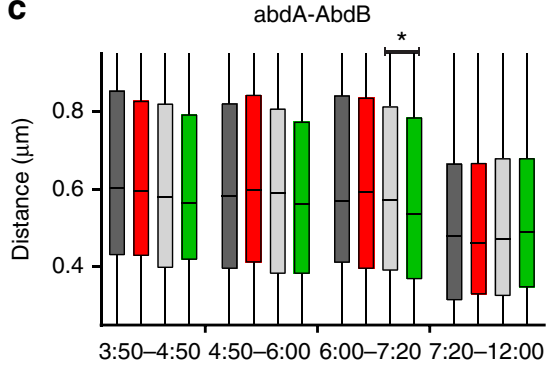

d

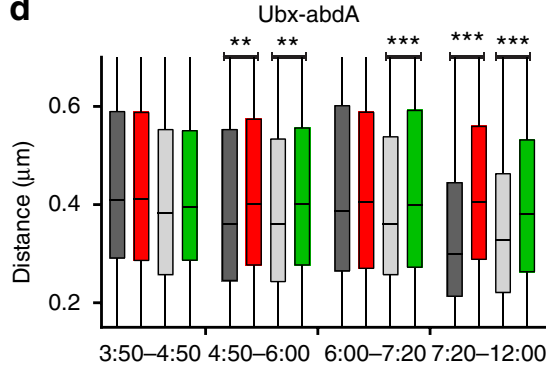

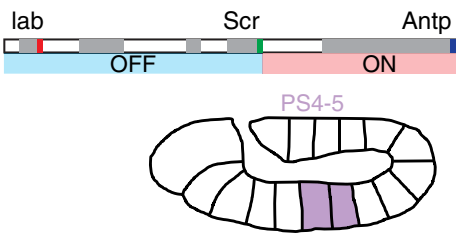

e

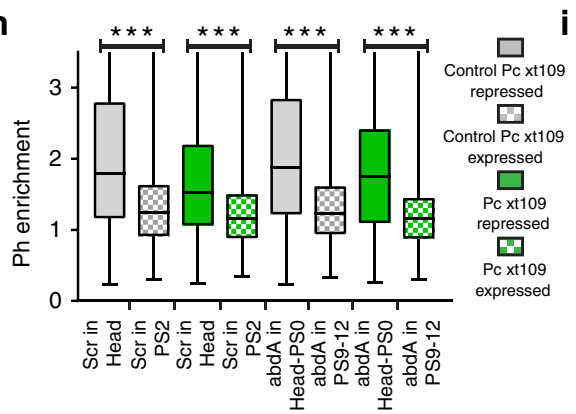

f
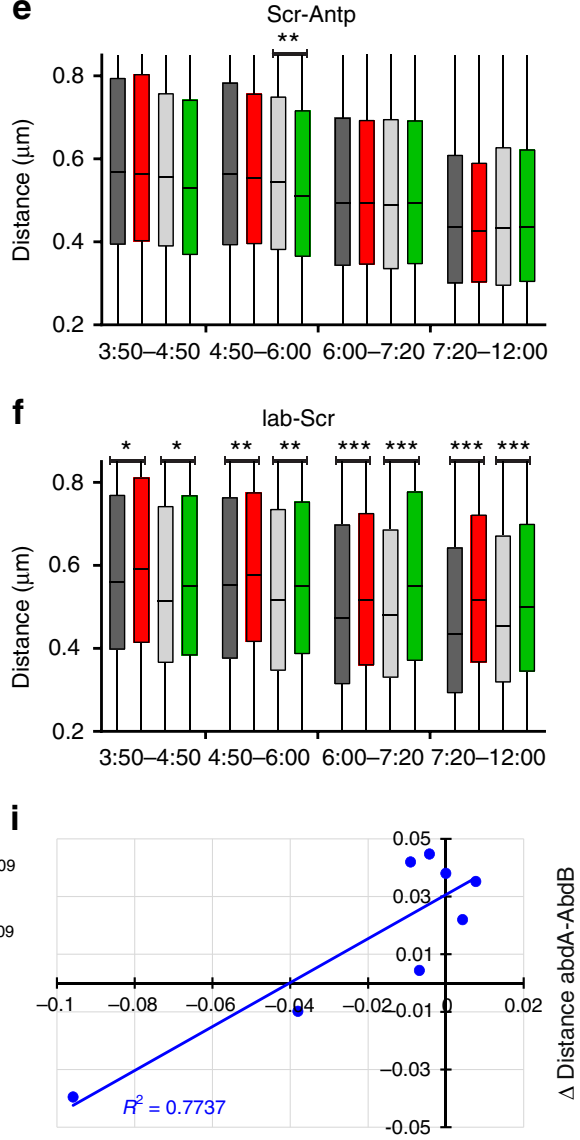

$\triangle \mathrm{abdA}$ expression

j

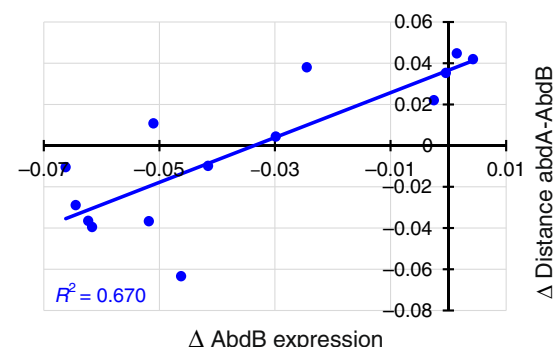

$\mathbf{k}$

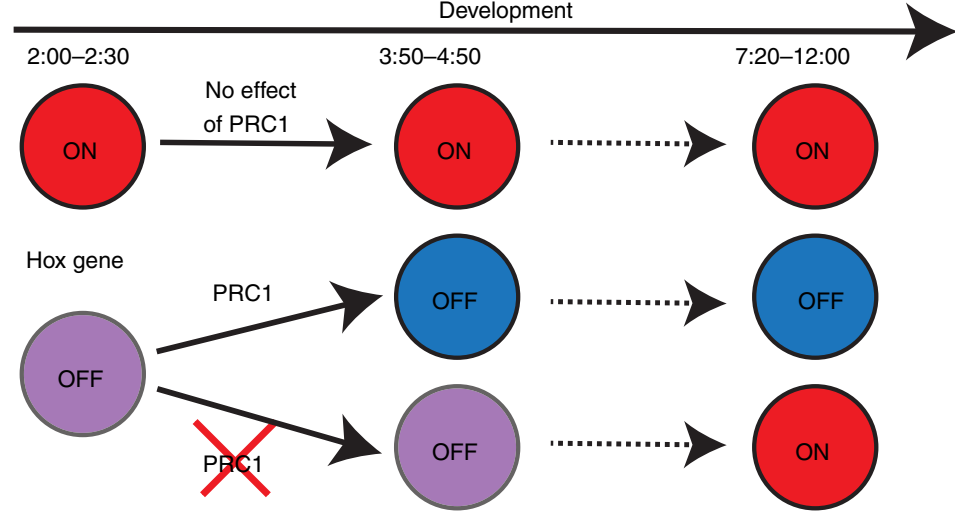

concentration of formamide. Primers used to synthesize DNA FISH probes hybridizing with the promoters of $U b x, a b d A, A b d B$, lab, Scr, and Antp are listed in Supplementary Table 1. Immuno-DNA FISH experiments were performed using either an anti-Pc rabbit polyclonal antibody (dilution 1/200) or an anti-Ph goat polyclonal antibody (dilution 1/500) developed in our laboratory 40 as primary detection antibodies with A405-conjugated secondary antibodies (anti-rabbit: Thermo Fisher Scientific; A-31556; dilution 1/200 or anti-goat: abcam; Ab 175664; $37^{\circ} \mathrm{C}$ in a solution containing $50 \%$ formamide, $2 \times$ SSC, and $0.3 \%$ CHAPS. embryos were transferred in $\mathrm{PBT}$ solution by progressively decreasing the 
Fig. 5 CPRC1 only compacts chromatin in the repressed regions of the BX-C and ANT-C domains. a-f Box plots displaying distributions of the distances $a b d A-A b d B(\mathbf{a}, \mathbf{c}), U b x-a b d A(\mathbf{b}, \mathbf{d}), \operatorname{Scr}-\operatorname{Antp}(\mathbf{e})$, and $\operatorname{lab}-\mathrm{Scr}(\mathbf{f})$ measured in the cell nuclei of Phdel embryos (red) and their respective controls (dark gray) or Pc XT109 embryos (green) and their respective controls (light gray). Measurements were made in PS9-12 (a, b), PS14 (c, d), and PS4-5 (e, f) during development. Distances distribution are comprised between 0 and $1.5 \mu \mathrm{m} . \mathbf{g}, \mathbf{h}$ Box plots presenting Pc (g) and Ph (h) enrichments at Scr and abdA FISH spots. Distribution of Pc and Ph enrichments are comprised between 0.2 and 11.33. The lower and upper bounds of the colored rectangles correspond to the first and third quartiles, whereas the middle bars indicate the median distances (a-h). Significant differences are indicated (Mann-Whitney, $U$-test, two-tailed, $\left.{ }^{\star} P<0.05 ;{ }^{\star \star} P<0.01 ;{ }^{* \star} P<0.001\right)(\mathbf{a}-\mathbf{h}) . \mathbf{i}, \mathbf{j}$ Scatterplots showing correlations between the differential effect of Ph and Pc on the distance $a b d A-A b d B$ at 3:50-4:50 and the differential effect of Ph and Pc on $a b d A$ or AbdB expression at 4:50-6:00. Each point corresponds to one PS where abdA (i) or $A b d B(\mathbf{j})$ are repressed in WT embryos. $\mathbf{k}$ Schematic diagram summarizing the effects of PRC1 on Hox gene folding and transcription. Circles represent silenced (OFF) or transcribed (ON) chromatin associated with Hox genes (red, open; purple, partly compact; blue fully compact). cPRC1 has no effect when Hox genes are expressed and chromatin is open. When Hox genes are repressed, cPRC1 compacts their chromatin during early embryogenesis and they will remain silenced. Without CPRC1, this compaction cannot occur and silenced Hox genes might become subsequently transcribed

dilution 1/200). FISH probes were directly labeled with A555 ( 6.4 pmol/ $\mu$ l for a DNA concentration of $\sim 70 \mathrm{ng} / \mu \mathrm{l}, U b x$ or lab), A488 ( 11 pmol/ $\mu \mathrm{l}$ for a DNA concentration of $\sim 75 \mathrm{ng} / \mu \mathrm{l}, a b d A$ or $S c r)$, or A647 ( $\sim 3.6 \mathrm{pmol} / \mu \mathrm{l}$ for a DNA concentration of $\sim 50 \mathrm{ng} / \mu \mathrm{l}, A b d B$ or Antp). Typically, we added $1.2 \mu \mathrm{l}$ of three probes containing either A488, A555, or A647 to $50 \mu \mathrm{l}$ of hybridization buffer. ImmunoFISH experiments were performed on embryos collected from Oregon- $\mathrm{R} \mathrm{w}^{1118}$, $p h^{d e l} / \mathrm{FKG}$, or $P c^{X T 109} / \mathrm{TKG}$ flies. Ph and Pc immunolabelling, respectively, allowed us to discriminate mutants from controls since $\sim 25 \%$ of the embryos were devoid of $\mathrm{Ph}$ or Pc from developmental stage 9 to the end of embryogenesis. Therefore, distance measurements done in embryos lacking $\mathrm{Ph}$ or Pc correspond to results of mutant embryos, whereas distance measurements done in embryos with normal levels of $\mathrm{Ph}$ or Pc were used as controls. Both balancer chromosomes FKG and TKG did not affect the folding of Hox gene clusters since no difference have been observed between WT, $\mathrm{Ph}^{\text {del }}$ control, and $\mathrm{Pc}^{\mathrm{xt} 109}$ control embryos. To evaluate chromatic aberrations, we performed FISH experiments with three probes (A448, A555, and A647) that hybridized to only one locus (Antp), and we measured the distances between the three different labels. The median distance between A488 and A555 was $130 \mathrm{~nm}$, between A555 and A647 was $120 \mathrm{~nm}$, and between A488 and $\mathrm{A} 647$ was $195 \mathrm{~nm}$.

We used A488-conjugated anti-rabbit (Thermo Fisher Scientific; A-21206; dilution 1/200) and A555-conjugated anti-goat (Thermo Fisher Scientific; A-21432; dilution 1/200) secondary antibodies for $\mathrm{Pc}$ and $\mathrm{Ph}$ double immunolabelling experiments. Pc/Ph immuno-DNA FISH experiments were performed using either Scr or abdA DNA probes coupled to A488. We used A555-conjugated anti-rabbit (Thermo Fisher Scientific; A-31572; dilution 1/200) and A647-conjugated anti-goat (Thermo Fisher Scientific; A-21447; dilution 1/200) secondary antibodies to detect anti-Pc and anti-Ph primary antibodies.

Microscopy and image analysis. Control and mutant genotypes were imaged and analyzed by using the same parameters in all the experiments performed in this work. Images were collected using a LSM 780 microscope (Carl Zeiss Microscopy, Iena) with a GaAsP detector and a $\times 60$ numerical aperture (NA) 1.4 objective. Images of RNA FISH and double $\mathrm{Ph} / \mathrm{Pc}$ immunolabelling were acquired with a pixel size of $110 \mathrm{~nm}$ and a $\mathrm{z}$-step of $0.5 \mu \mathrm{m}$. I-FISH experimental images had pixels of $73 \mathrm{~nm}$ and a $\mathrm{z}$-step of $0.3 \mu \mathrm{m}$ to measure the 3D distance between three FISH signals, whereas double $\mathrm{Pc} / \mathrm{Ph}$ immunolabelling coupled with single FISH (Fig. $5 \mathrm{~g}, \mathrm{~h}$ and Supplementary Fig. $11 \mathrm{~g}$, h) were acquired with a pixel size of $94 \mathrm{~nm}$ and a $\mathrm{z}$-step of $0.3 \mu \mathrm{m}$. RNA FISH experiments were quantified using ImageJ software. First, a Gaussian filter with a radius of 1 was applied to reduce noise. Z-projection was then calculated using maximum intensity projection. Second, areas corresponding to the PSs of interest were manually drawn. We then measured their surface area and counted the number of FISH spots using the option "find maxima".

Distances between DNA FISH signals were measured using Volocity software (Perkin Elmer, Coventry). A fine $(3 \times 3 \times 3$ pixels $)$ filter was applied to reduce noise, and the three FISH signals were segmented using the threshold option "get objects". PSs were drawn manually, and we measured distances between the centers of mass of segmented objects in each PS of one embryo. For each object corresponding to one FISH spot, we computed the two distances with the two closest objects of the two other FISH signals and we only kept measurements when these two distances were below $1.5 \mu \mathrm{m}$. Therefore, measurements have only been made when one FISH spot for the three different FISH probes can be detected within a radius below $1.5 \mu \mathrm{m}$. In this study, distance measurements have been presented in two ways. On the one hand, distances coming from several embryos of the same conditions were pooled (i.e. same PS, same developmental stage and same type of embryos). We then plotted their global distributions comprised between 0 and $1.5 \mu \mathrm{m}$ and used Mann-Whitney $U$-test to compare their distributions obtained in two different conditions (Figs. 3 and 5; Supplementary Fig. 8). On the other hand, we computed the median distances $U b x-A b d B, a b d A-A b d B$, and $U b x-$ $a b d A$ (Fig. 1; Supplementary Fig. 9) or lab-Scr, Scr-Antp, and lab-Antp (Fig. 1; Supplementary Fig. 10) for each PS of one embryo. Median distances have been calculated in several embryos of the same condition, and we then plotted their mean along the $\mathrm{A} / \mathrm{P}$ axis. Here, we used the $t$-test to compare two conditions. Both ways of analyzing distance measurements give the same conclusions. To globally visualize the effects of $\mathrm{Ph}, \mathrm{Pc}$, and Hox gene transcription on folding of BX-C and ANT-C, median distances were corrected for chromatic aberrations (Fig. 3n-p and Fig. 4h-j). Images shown in Supplementary Fig. 5-7 were done with the option "3D opacity" and the mode "maximum intensity" of the Volocity software.

To quantify the enrichment of $\mathrm{Pc} / \mathrm{Ph}$ in nuclear foci (Supplementary Fig. 11), we used Image-J software to perform a Gaussian filter (radius $=1$ ) and a $3 \mu \mathrm{m}$ thick maximum intensity projection. Then, we computed local maxima and average nuclear intensity in 25 nuclei located in the head. Similarly, we used Image$\mathrm{J}$ software to quantify $\mathrm{Pc} / \mathrm{Ph}$ enrichment at $S c r$ and $a b d A$ loci (Fig. $5 \mathrm{~g}, \mathrm{~h}$ ). We performed a Gaussian filter (radius $=1$ ) and used the FISH channel to compute local maximum corresponding to FISH spots. Then, we measured the pixel intensity in the channel corresponding to $\mathrm{Ph}$ or $\mathrm{Pc}$ immunolabelling at the local maxima previously identified. We divided the later intensity with the average nuclear intensity to calculate Ph or Pc enrichments. Finally, we used Mann-Whitney $U$-test to compare distributions obtained in two different conditions.

\section{Data availability}

The data sets generated during the current study are available from the corresponding authors upon request.

Received: 6 January 2018 Accepted: 30 July 2018

Published online: 25 September 2018

\section{References}

1. Geisler, S. J. \& Paro, R. Trithorax and Polycomb group-dependent regulation: a tale of opposing activities. Development 142, 2876-2887 (2015).

2. Jaensch, E. S., Kundu, S. \& Kingston, R. E. Multitasking by Polycomb response elements. Genes Dev. 31, 1069-1072 (2017).

3. Schuettengruber, B., Bourbon, H. M., Di Croce, L. \& Cavalli, G. Genome regulation by Polycomb and trithorax: 70 years and counting. Cell 171, 34-57 (2017).

4. Schuettengruber, B. et al. Functional anatomy of polycomb and trithorax chromatin landscapes in Drosophila embryos. PLoS Biol. 7, e13 (2009).

5. Sexton, T. et al. Three-dimensional folding and functional organization principles of the Drosophila genome. Cell 148, 458-472 (2012).

6. Cheutin, T. \& Cavalli, G. Progressive polycomb assembly on H3K27me3 compartments generates polycomb bodies with developmentally regulated motion. PLoS Genet. 8, e1002465 (2012).

7. Wani, A. H. et al. Chromatin topology is coupled to Polycomb group protein subnuclear organization. Nat. Commun. 7, 10291 (2016).

8. Pirrotta, V. \& Li, H. B. A view of nuclear Polycomb bodies. Curr. Opin. Genet. Dev. 22, 101-109 (2012).

9. Lanzuolo, C., Roure, V., Dekker, J., Bantignies, F. \& Orlando, V. Polycomb response elements mediate the formation of chromosome higher-order structures in the bithorax complex. Nat. Cell Biol. 9, 1167-1174 (2007).

10. Eskeland, R. et al. Ring1B compacts chromatin structure and represses gene expression independent of histone ubiquitination. Mol. Cell 38, 452-464 (2010).

11. Kundu, S. et al. Polycomb repressive complex 1 generates discrete compacted domains that change during differentiation. Mol. Cell 65, 432-446 e435 (2017).

12. Schwartz, Y. B. \& Pirrotta, V. Polycomb silencing mechanisms and the management of genomic programmes. Nat. Rev. Genet. 8, 9-22 (2007).

13. Wedeen, C., Harding, K. \& Levine, M. Spatial regulation of Antennapedia and bithorax gene expression by the Polycomb locus in Drosophila. Cell 44, 739-748 (1986). 
14. Lewis, E. B. A gene complex controlling segmentation in Drosophila. Nature 276, 565-570 (1978)

15. Harding, K., Wedeen, C., McGinnis, W. \& Levine, M. Spatially regulated expression of homeotic genes in Drosophila. Science 229, 1236-1242 (1985).

16. Maeda, R. K. \& Karch, F. The open for business model of the bithorax complex in Drosophila. Chromosoma 124, 293-307 (2015).

17. Holoch, D. \& Margueron, R. Mechanisms regulating PRC2 recruitment and enzymatic activity. Trends Biochem. Sci. 42, 531-542 (2017).

18. Fischle, W. et al. Molecular basis for the discrimination of repressive methyllysine marks in histone H3 by Polycomb and HP1 chromodomains. Genes Dev. 17, 1870-1881 (2003).

19. Francis, N. J., Kingston, R. E. \& Woodcock, C. L. Chromatin compaction by a polycomb group protein complex. Science 306, 1574-1577 (2004).

20. Grau, D. J. et al. Compaction of chromatin by diverse Polycomb group proteins requires localized regions of high charge. Genes Dev. 25, 2210-2221 (2011).

21. Lau, M. S. et al. Mutation of a nucleosome compaction region disrupts Polycomb-mediated axial patterning. Science 355, 1081-1084 (2017).

22. Boettiger, A. N. et al. Super-resolution imaging reveals distinct chromatin folding for different epigenetic states. Nature 529, 418-422 (2016).

23. Schoenfelder, S. et al. Polycomb repressive complex PRC1 spatially constrains the mouse embryonic stem cell genome. Nat. Genet. 47, 1179-1186 (2015).

24. Dekker, J. \& Heard, E. Structural and functional diversity of topologically associating domains. FEBS Lett. 589, 2877-2884 (2015).

25. Cheutin, T. \& Cavalli, G. Polycomb silencing: from linear chromatin domains to 3D chromosome folding. Curr. Opin. Genet. Dev. 25, 30-37 (2014).

26. Kosman, D. et al. Multiplex detection of RNA expression in Drosophila embryos. Science 305, 846 (2004).

27. Roumengous, S., Rousset, R. \& Noselli, S. Polycomb and Hox genes control JNK-induced remodeling of the segment boundary during Drosophila morphogenesis. Cell Rep. 19, 60-71 (2017).

28. Bowman, S. K. et al. H3K27 modifications define segmental regulatory domains in the Drosophila bithorax complex. eLife 3, e02833 (2014).

29. Papp, B. \& Muller, J. Histone trimethylation and the maintenance of transcriptional ON and OFF states by trxG and PcG proteins. Genes Dev. 20, 2041-2054 (2006).

30. Simon, J., Chiang, A. \& Bender, W. Ten different Polycomb group genes are required for spatial control of the abdA and AbdB homeotic products. Development 114, 493-505 (1992).

31. Dura, J. M. \& Ingham, P. Tissue- and stage-specific control of homeotic and segmentation gene expression in Drosophila embryos by the polyhomeotic gene. Development 103, 733-741 (1988).

32. Kumar, J. P. \& Moses, K. Expression of evolutionarily conserved eye specification genes during Drosophila embryogenesis. Dev. Genes Evol. 211, 406-414 (2001).

33. Guss, K. A., Mistry, H. \& Skeath, J. B. Vestigial expression in the Drosophila embryonic central nervous system. Dev. Dyn. 237, 2483-2489 (2008).

34. Zhang, C. C. \& Bienz, M. Segmental determination in Drosophila conferred by hunchback (hb), a repressor of the homeotic gene Ultrabithorax (Ubx). Proc. Natl. Acad. Sci. USA 89, 7511-7515 (1992).

35. Isono, K. et al. SAM domain polymerization links subnuclear clustering of PRC1 to gene silencing. Dev. Cell 26, 565-577 (2013).

36. Kahn, T. G. et al. Interdependence of PRC1 and PRC2 for recruitment to Polycomb response elements. Nucleic Acids Res. 44, 10132-10149 (2016).

37. Feng, S., Huang, J. \& Wang, J. Loss of the Polycomb group gene polyhomeotic induces non-autonomous cell overproliferation. EMBO Rep. 12, 157-163 (2011).
38. Franke, A., Messmer, S. \& Paro, R. Mapping functional domains of the polycomb protein of Drosophila melanogaster. Chromosome Res. 3, 351-360 (1995).

39. Bantignies, F. \& Cavalli, G. Topological organization of Drosophila Hox genes using DNA fluorescent in situ hybridization. Methods Mol. Biol. 1196, 103-120 (2014).

40. Grimaud, C. et al. RNAi components are required for nuclear clustering of Polycomb group response elements. Cell 124, 957-971 (2006).

\section{Acknowledgements}

We acknowledge the Drosophila and imaging MRI facilities, member of the National Infrastructure France-BioImaging supported by the French National Research Agency (ANR-10-INBS-04, "Investments for the future"). We thank Satish Sati and Frédéric Bantignies for critical reading of the manuscript. G.C. Research in the laboratory of G.C. was supported by grants from the European Research Council (ERC-2008-AdG no. 232947), the CNRS, the FP7 European Network of Excellence EpiGeneSys, the European Union's Horizon 2020 research and innovation program under grant agreement No. 676556 (MuG), the Agence Nationale de la Recherche (N. ANR-15-CE12-006-01), the Fondation pour la Recherche Médicale (Grant no. DEI20151234396), the French National Cancer Institute (INCa, Project no. PLBIO16-222), and the Laboratory of Excellence EpiGenMed (No. ANR-10-LABX-12).

\section{Author contributions}

T.C. and G.C. initiated and led the project. T.C. performed experiments and data analysis. T.C. and G.C. interpreted and discussed the data and wrote the manuscript.Data availabilityThe data sets generated during the current study are available from the corresponding authors upon request.

\section{Additional information}

Supplementary Information accompanies this paper at https://doi.org/10.1038/s41467018-05945-4.

Competing interests: The authors declare no competing interests.

Reprints and permission information is available online at http://npg.nature.com/ reprintsandpermissions/

Publisher's note: Springer Nature remains neutral with regard to jurisdictional claims in published maps and institutional affiliations.

pen Access This article is licensed under a Creative Commons Attribution 4.0 International License, which permits use, sharing, adaptation, distribution and reproduction in any medium or format, as long as you give appropriate credit to the original author(s) and the source, provide a link to the Creative Commons license, and indicate if changes were made. The images or other third party material in this article are included in the article's Creative Commons license, unless indicated otherwise in a credit line to the material. If material is not included in the article's Creative Commons license and your intended use is not permitted by statutory regulation or exceeds the permitted use, you will need to obtain permission directly from the copyright holder. To view a copy of this license, visit http://creativecommons.org/ licenses/by/4.0/.

(c) The Author(s) 2018 